\title{
EDITORIAL: TURKICIZATION AND RONDOLOGY IN MOZART'S SONATA IN A MAJOR, K 331
}

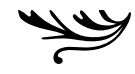

It seems that all one has to do is add a suffix to a more or less normal word in order to bring it into the world of the academy. This has been going on for years. A relatively straightforward term like pentatonic expanded into monsters like 'pentatonicism' and 'pentatonicization'; method became 'methodologically', tonic 'tonicize', and chromatic morphed to 'chromaticization'. Even a relatively humble word like 'exotic' quickly got its -ism and -ization. And perhaps we will even get exoticizationism soon. If all this lengthening were in the service of precision, who would care? What are a few characters more or less in a virtual world? But it may be worth considering once again that naming things is not the same as understanding them.

With this in mind, I would like to look briefly at one of the most famous pieces written in the eighteenth century: Mozart's Alla turca from the Sonata in A major. Notice, I did not say 'rondo', because Mozart does not call it that, and for all its possible rondo-like features, it doesn't always behave like a rondo. About this, more later.

I could provide you now, as evidence of my seriousness, with a complete historical background for the work. But actually, it would mostly be fiction or irrelevant, because the vast majority of the important things about this piece and its composition are unknown. If we simply start with what we do not know about the Alla turca, we will have enough to occupy us as long as we continue to investigate. As of this moment there is no agreement about the date of composition, nor do we know if (or in what ways) different datings might affect our understanding of the work. We do not know if the piece was written for a particular instrument with a Turkish stop. (I thank the editors for reminding me of this.) This is not to say that we know nothing about the piece. We certainly know enough to fill the 'floppy disk' of most readers (Mozart could have written it on this or that date, he used the Turkish style elsewhere, it is in such and such a key, etc. etc.), and we could certainly add requisite documentation to show both industry (showing sweat stains seems to be an important part of our field) and science, thus projecting a certain pose of authority that could certainly be evidence of serious inquiry at the highest level - or simply pedantry and pretension.

We use words to present our findings, and, of course, one can say anything. So if I were to write, say, that Mozart's 'Turkish' Rondo is a matter of 'the West gazing at the East', or that 'it encodes imperial strategies', or that it 'stands as a bold monument to alterity' or 'the Other' you would know, or should know, that these are simply words, words that are so much a part of the landscape of academic writing that they have become almost invisible, and in many cases, ceased to have any real meaning or value. What they might purport can never be proven or really explicated (Well $I$ hear imperialism. Well $I$ don't!). No scientific model can be tested here, and no control group exists to sharpen the hypothesis. No suggestion is made of what we might need to investigate in order to shore up such statements, so let me try to come up with a few possible strategies.

There are at least three painfully difficult things we would have to understand before we could speak about the sonata movement with anything like confidence. We would first have to demonstrate that, beyond wishful thinking and our belief system of the moment, there really is a precise connection between a range of ideological issues and the instigation and completion of a musical composition. I tediously say 'instigation and completion' because it might be possible that the impulse to create a certain kind of piece is rooted in real-world politics, but its 'working-out' is a more inscrutable process. Or the opposite could be true: the actual choice of medium, style, key and so forth might be fairly abstract and benign; the real evidence of the work as 'cultural product' is in the detailed process of composition. The fact that we cannot say one way or the other is an indication of the problem. 
Second, we would actually have to make some kind of a model to reflect Mozart's thinking on the subject. If the great figures in critical studies are allowed to have ideas and points of view, we might cede to the composer the right to have them too. However, we must admit that we have only the fuzziest idea about what Mozart might have thought about his material in this case, why he chose it, what is a joke and what is serious, and how we might demonstrate any of it. Of course we could widen our lens a bit and look at 'Mozart and His World'. Yet even if we had the evidence to argue for a 'Viennese World View', it simply does not work to say 'eighty percent of Viennese had such opinions, therefore we can assume that Mozart had them as well' or that 'composers express the collective will of their age'. Again, those are statements of belief, not scholarship or science, with no more claim to authority than a fundamentalist sermon in a rural church in Tennessee.

This leads to the final task, to figure out just how the various pieces of a composition might work together to have the potential to tell some kind of a story, or at least have enough traction to be evidence of anything, especially evidence of the kind of academic conspiracy theory that can be found all too often of the 'this march encodes militarism' variety. It is always worth noting that the notions that the West imposes its will on the East, or that the West is a repository of elitism, or that 'Othering' ought to be a federal crime punished by prison time, are inevitably couched in the fashionable 'elitisms' of the West. No one has yet sought to make their case in blues lyrics. So we understand that in today's academic world the argument against, say, journals with arcane subjects and dense and opaque writing will be made in those same journals using arcane arguments and employing dense and opaque writing.

We do not have much evidence of Mozart's political thinking, and, as I have suggested, finding a diary entry written by such and such a Count, or a newspaper article, or an illustration, can never be evidence of what Mozart thought or meant. And even if we had a document called 'Yo Scholar! Here's Why I Wrote the Alla turca', authentically signed by Mozart, the same level of critical theorizing that created the concept of 'the exotic' would mandate that we deconstruct Mozart's words and problematize those very things that, in a previous paradigm, allowed us to make strong arguments. Once again we must confront the fact that the largest cache of evidence in this case, such as it is, comes to us with enormous precision in something called a musical score, surely one of the most astonishing records of the past ever invented. It goes without saying that there are those who believe that the realized product of this score does not have meaning outside its own systems of reference, and others who might insist that it does have an external meaning that is, however, inscrutable. For those still searching, we have the usual choices in order to unpack it. We can analyse it, that is, break it down into parts, or subject it to some accepted theoretical approach. We can view it alongside other examples, either contemporary or not, and try to articulate the ways in which it is distinctive. We can experience it (as performer or audience) and hope that when we search for words to describe that experience, something useful remains. We can start with a particular critical theory or discourse and try to find evidence for it in the work. Or we can even 'pretend' not to know exactly what we will find; we can pretend to be objective.

Let's further up the ante by beginning not with what we think we know about Mozart's Alla turca, but what we do not know. So, we begin by not knowing how to imagine what a 'movement' actually is in relation to 'a whole composition'. Unlike a chapter in a novel or an act of a play, it is somewhat self-sufficient. Particularly a war-horse like the Alla turca (or should that be war-pony) seems to need nothing else to complete it, especially not the throwaway minuet that precedes it. But we do labour under the notion that the 'work of art', or whatever we call it, is at the level of the entire composition. The problem, of course, is that just about all our analytical systems work at the level of the individual movement and generally cannot deal with the whole with anything even approaching similar precision.

Even if we do take the last movement as the 'object' of our study, it wriggles out of our grasp whenever we try to hold it. What does it mean to call this piece a 'rondo'? Is the refrain the famous section in A major, or is it rather the double minor/major succession that marks the piece's identity? In other words, if the 'rondo subject' in simple-minded formal analysis should be marked as ' $\mathrm{A}$ ', does 'A' consist of the long opening passage up to bar 32 ? Or is the rondo refrain more properly bars $25-32$, as might be implied by its return after 
the passage in F sharp minor at bar 32 (of course it is really bar 64, since no one numbers repeats)? If we accept the 'long A' as the refrain, then the piece is basically nothing but refrain, with one small detour. However, if we were to consider the A major section as the refrain, would we then start our alphabet soup of the piece with ' $\mathrm{B}$ ' (the refrain before the refrain?)? And does any of this matter for our apprehension of the whole?

If we were determined to move away from these so-called technical considerations for a moment and open things out to a more general inquiry, I am not sure the first stop would be 'the exotic'. Rather, we might wonder whether Mozart calls the piece Alla turca because he is doing some things that would be misunderstood if he did not so designate it. You do not have to explain harmonic oddness if you have identified a substance as 'Turkish' any more than you have to explain why you used certain kinds of dissonance in a composition called 'The Big Storm Blows the House Over'. The question of why Mozart is using a minor dominant, or banging merrily away at tonic chords, is easily answered by 'it's Alla turca!' Or another possibility, 'I'm using a Turkish stop on my instrument with a buzzing A!'.

Those many, many pianists who have played the piece might also imagine that even beyond sound Mozart had in mind some special tactile sensations when he conceived of the Alla turca. All who have spent time with it have some visceral sense of how that opening feels, the ascending turns in the right hand alternating with the static left, the way the ornaments feel on the E minor chord in the right hand, the ornamental arpeggios in the left hand in the A major section. These, too, are a vital part of the conception.

We might also consider that rather than being a reflection of Mozart's attitude towards the East, the piece might just as easily offer evidence of his take on the cultural politics of the Habsburg Empire where he lives. After all, one 'style' of Mozart's is the 'style of styles', where, as in the opening of the next sonata in the catalogue, $\mathrm{K} 332$, we may experience a dizzying succession of unlike stylistic worlds within a limited space - in the first thirty or so bars of K332 we range from cantilena to an alla barocco canon, and from a children's march to Sturm und Drang. Thus the wild and flamboyant juxtapositions in the Alla turca might represent the musical argot of the polyglot Empire, not Mozart's take on world domination or an example of Said's 'orientalizing'.

Empire or not, one of Mozart's favourite games, and one of the favourite games of the age, as it were, is to see how much opposition can possibly coexist in a finite musical space (see the 'Turkish' section in the Violin Concerto No. 5 in A major, K219, or the 'Turkish' march in the finale of Beethoven's Ninth Symphony as examples of such strong contrast). Perhaps, then, Mozart has reached into an entirely different musical realm in order to ratchet up the aesthetic of opposition he craves. Depending on one's view, the coda could reflect Marx - Groucho or Karl - as either the apotheosis of comic anarchy or an attempted post-Hegelian synthesis of the movement's economy of opposition. And it further goes without saying, as a wise editor pointed out recently, that making comments on Mozart's 'special' qualities without having done a thorough study of the music of his contemporaries is another hazard rarely avoided.

We're still not through with the piece, of course. Though the A major section occurs most often, there is no proof of any kind that the refrain, or whatever we decide it is, has real primacy. Musical works cannot be reduced to formulas suggesting that what we hear first or what we hear most often is the most important. In fact, the opposite could be just as true, especially since there is no way to test either hypothesis. We could certainly insist that what happens in the middle is, in fact, the most significant: the 'middle' is what the composer has decided to do after tending to the processes of starting and ending, aspects that require energy and structural planning. Middles, like the passage beginning at bar 32, occur only once and are thus unique; middles are filled with 'things that are not permitted to touch the rest of the world', they are what the composer chooses to do when free to do almost anything he or she likes. Middles may sometimes be forgotten when we call up pieces from our memories, but that amnesia, far from 'marginalizing' such moments, gives them even greater strength as what we might call a work's unconscious. Now, the previous sentence may strike you as absolutely true, or as a blast of hot air, but it is no more or less sustainable than the assumption that the opening of a piece should be equated with its identity, and no more or less subject to proof. 
However, since we have called attention to it, we may well ask just what is happening in the very centre of the Alla turca. In his over-the-top elaboration of the piece, called 'The Turkish March', pianist Arkady Volodos shows the connection between the opening bars and the stuff in the middle by simply combining the two. This is simultaneously a witty conceit, suggesting a kinship that is worth noting, and an opportunity for virtuoso display. Cheap or not, it does raise a question: is the F sharp minor section in the centre simply a continuation of the variation principles of the sonata's first movement, or are the differences here at least as instructive as the similarities?

Featuring the kind of perpetuum mobile that would become famous with Paganini and others, the passage uses practices that later culminate in such classics of the sub-genre as the 'Flight of the Bumblebee'. Whether this is somehow to be construed as Turkish, an example of musical 'Gypsiness' (see the 'middle' to the finale of Brahms's Piano Quartet in G minor) or Mozart's own invention hardly matters. Here, in the work's soft centre, we have something like pure movement, yet, because of that, paradoxically devoid of real forward motion. If the Alla turca's opening gesture is an elaboration of pure motive, the middle is design without symbolic intent. The fact that the previous sentence is inscrutable makes it neither brilliant nor automatically nonsense. It could be both or neither.

If we were to follow through with some of these thoughts, we could even argue that the piece is purposely written inside out. Of course the A major part is the rondo refrain. Mozart has simply done it all backwards: the first episode comes before the refrain, and in effect, announces it, as does the second episode in $\mathrm{F}$ sharp minor. So the piece might be sketched as $\mathrm{B}-\mathrm{A}-\mathrm{C}-\mathrm{A}-\mathrm{B}-\mathrm{A}$ (coda=AB synthesis). The Alla turca is thus a travesty, a joke, a perversion, and it is precisely in the moto perpetuo middle and the coda where the trick is revealed.

Again, none of this is provable, and 'rigorous' argument is no more a recipe for profundity than its opposite - in fact certain kinds of rigour in a field not based on control groups can easily descend to mere rhetorical bullying. And it follows that if we cannot even say how the structure unfolds in such a simple piece, and what might be primary and what is secondary, and if we know not a thing about Mozart's opinions concerning his Turkish style - both external explanations and any internal ones he would not articulate himself - we are a long way from being able to make convincing arguments about the 'meaning of the exotic in Mozart'.

With all the words being bandied around in today's jargon-ridden landscape, two seem to be missing: null hypothesis. This sets a standard for what one must prove in order to make certain arguments. These two words might help us in the roiling, storm-tossed waters of our field. For our ship sails most true when we spend more time admitting what we do not know than showing what (we think) we do.

MICHAEL BECKERMAN 